\title{
Effects of different types of verbal encouragement on ankle force and muscle activity
}

http://dx.doi.org/10.11606/1807-5509201800040699

\begin{tabular}{|c|c|}
\hline $\begin{array}{r}\text { Ulisses T. TADDEI* } \\
\text { Francis TROMBINI-SOUZA* } \\
\text { Jane S. S. P. FERREIRA* } \\
\text { Alessandra B. MATIAS } \\
\text { Rafael S. INOUE* } \\
\text { Fernanda I. A. RIBEIRO* } \\
\text { João V. L. DARE } \\
\text { João P. A. PANIGHEL } \\
\text { Renan CALORI* } \\
\text { Pamela A. SANTANA* } \\
\text { Milene E. DALFOLO* } \\
\text { Isabel C. N. SACCO* }\end{array}$ & $\begin{array}{l}\text { *School of Medicine, } \\
\text { University of Sao } \\
\text { Paulo, São Paulo, SP, } \\
\text { Brazil. } \\
\text { **Department of } \\
\text { Physical Therapy, } \\
\text { University of } \\
\text { Pernambuco, Recife, } \\
\text { PE, Brazil. }\end{array}$ \\
\hline
\end{tabular}

\section{Abstract}

The aim of this study is to investigate (i) the effect of live and recorded verbal encouragement on muscle activity and ankle force; (ii) the effect of communication/extroversion on the variables; (iii) the reliability intra and inter examiners of the variables. Twenty healthy-youngers were assessed by surface electromyography of tibialis anterior and ankle flexion force by an ergometer twice, with one week apart. No difference was found between ankle force ( $p=0.373)$ and root mean square values (RMS) $(p=0.207)$ for any of the conditions assessed on day 1 nor between examiners 1 and 2 for both live and recorded conditions in RMS $(p=0.207)$ and force $(p=0.373)$. Between the $1^{\text {st }}$ and $7^{\text {th }}$ days, there were no differences for any of the conditions on RMS (main effect "Day" $p=0.261$, "condition" $p=0.568$, interaction $p=0.936$ ) or force (main effect "Day" $p=0.889$, "condition" $p=0.781$, interaction $p=0.961$ ). Intraclass correlation coefficients (ICCS) for the ankle force were, for without verbal encouragement (ICC2, $k=0.880)$, live verbal encouragement of examiner 1 (ICC2, $k=0.870)$, and recorded verbal encouragement of examiner 1 (ICC2, $k=0.920)$. RMS without verbal encouragement condition (ICC2, $k=0.860)$, live verbal encouragement of examiner 1 (ICC2, $\mathrm{k}=0.930)$ and recorded verbal encouragement of examiner $1(\mathrm{ICC} 2, \mathrm{k}=0.920)$. Reproducibility between the two examiner's live encouragements for ankle force (ICC3, $k=0.981$ ) and RMS (ICC3, $k=0.920)$. There was no effect of the presence or type of the augmented feedback in RMS and ankle force. We conclude that verbal encouragement does not influence ankle torque or muscle activity and there is good to excellent intra and inter rater reliability for subjects' performance regardless of verbal encouragement modality. In addition, we observed that psychological traits Communication and Emotional stability does not affect the subjects' strength performance at the ankle.

KEYWORDS: Verbal encouragement; Augmented feedback; Electromyography; Force; Personality.

\section{Introduction}

It is usual in physical therapy interventions and physical activities the use of augmented feedback to encourage and improve the performance of a motor task. HowEver, it is unclear whether the response to this augmented stimulus may vary when its source changes in origin and in nature (live or recorded), although some studies reported that external stimuli can be an efficient way to enhance performance ${ }^{1-3}$. There are two possible types of stimuli: intrinsic or inherent stimulus and extrinsic or augmented feedback ${ }^{4,5}$. The first one leads the receiver to process his/hers own sensorial information, being capable of 
internalize and understand the need of adjusting or improving the task performance ${ }^{5}$. Extrinsic feedback consists of any information about the performance of a motor skill that is supplied by a source external to the performer and that supplements or adds to the performer's sensory feedback. Augmented external stimulus can be an instructive verbalization also known as verbal encouragement, can be provided previously or simultaneously to the task's performance and may focus also on the task goal or motivation ${ }^{6}$. Verbal encouragement may not necessarily be provided live but it can be provided by an equipment that transmits recorded standard verbal stimuli. Locally or recorded, verbal encouragements aim to raise the occurrence of intrinsic feedback and, consequently, the performance of a particular motor task ${ }^{6}$. Recorded encouragement, just like the live one, could also encourage a subject to improve his performance in a motor task. The advantage of a recorded stimuli is that it could be reproduced with less variability, for instance, throughout every section of a clinical trial without interference of the examiner, or in other types of intervention with high reliability.

It is believed that the social persuasion towards motivation and the subsequent internalization of it may be enhanced or weakened depending on the emotional state of a subject or even yet, depending on the aspects of one's personality such as extroversion and communication capabilities, therefore, influencing the performance of the motor task ${ }^{7,8}$. Self-determination theory determines that social and environmental factors facilitate or undermine motivation, using language that reflects the assumption that intrinsic motivation, being inherent, will be catalyzed when individuals are in conditions that conduce toward its expression. Therefore, studies on conditions that facilitate motivation is an important step in understanding sources of changes in motor performance in different circumstances?

Scientific evidences suggest that words of encouragement (motivation focus) might result in strength enhancement during an exercising session ${ }^{10}$. In addition, there is a correlation between the volume of such verbal encouragement and the strength of a demanded muscular contraction ${ }^{11}$. Another study has observed that using verbal encouragement increased performance of non-intrinsically motivated person to exercise ${ }^{12}$. In contrast, RUBE and SECHER ${ }^{13}$ did not find any difference on the performance of a series of knee extensors isometric contractions performed with and without verbal encouragement. And yet, on another study, CAmpenella et al..$^{14}$ concluded that verbal encouragement induced a decrease on quadriceps and hamstrings eccentric torque, particularly when compared to an association of visual and verbal stimulus, showing the low capability of verbal encouragement on enhancing motor performance.

Despite of being a common practice during motor task learning and training, the efficacy of motivational verbal encouragement is still controversial. A possible factor that might influence the use of verbal encouragement is the reliability of such given stimulus. Little is known about the reliability and reproducibility of external encouragement and how much it influences the increment on the motor task performance. It is possible that unknown factors, such as particular personality traits of the person giving the verbal encouragement and the person receiving it, could mislead the reliability results ${ }^{7}$. The inter-examiner variability in the command given could lead to different results on performance. Only studies with more than one examiner are capable to verify whether or not different examiners are responsible for performance variability in the presence of augmented feedback ${ }^{10}$. Furthermore, other studies that use only one type of verbal command: recorded ${ }^{7}$ or live ${ }^{10}$, are ineffective on verifying if there are differences between these conditions. Previous studies that investigated the role of the verbal augmented feedback did not access the effect of the personality differences, thus, it is still unknown whether personality traits such as conscientiousness, may have an impact on the levels of muscle contraction and strength in the absence or presence of verbal encouragement ${ }^{7}$.

Therefore, to further understanding the effects of different verbal encouragements on muscle strength, a simple task with only one degree of freedom should be assessed to minimize the angular variability in other planes during the assessment. In clinical practice, it is common to assess indirectly joint force production by means of surface electromyography (EMG) and isometric joint torque. The muscle choice should be based on how important it is for the task and how easily accessible it is for the measurements. Taking into account both aspects mentioned before, isometric ankle flexion torque and tibialis anterior surface EMG are a very reliable choice for being assessed and testing the isolated effect verbal encouragement in a very simple and controlled task. In addition, two different examiners should give the verbal encouragements in with two conditions - live and recorded, thus the effects of 
variation on the results can be controlled and all aspects of the reliability can be assessed.

It is important to highlight that, the influence of verbal encouragement should be assessed not only in trained population and high performance athletes that are used to receive verbal encouragement and respond accordingly, but also in individuals that are receiving physiotherapy, sedentary people and novice athletes on clinical practice and sports training, because they are also subject to receive verbal feedback and encouragement and are not used to that practice. Given that, we can enhance the external validity of verbal encouragement in diverse populations to test its effects.

Thus, the aims of this study were: (i) compare different types of verbal encouragement (live, recorded and absence) during ankle isometric flexion on tibialis anterior muscle activity and force; (ii) investigate the effect of the psychological traits communication / extroversion on tibialis anterior muscle activity and isometric ankle flexor force when submitted to different types augmented verbal encouragement; (iii) evaluate the intra and inter rater reliability on the subjects performance of ankle flexion considering the type of stimulus. Our hypothesis were: (i) ankle flexor force magnitude and muscle activity are greater with live verbal encouragement (LVE) when compared to recorded verbal encouragement (RVE), and in both situations, greater when compared to the condition without verbal encouragement (WVE); (ii) psychological traits "communication" and "Emotional stability" influence EMG activity and ankle force when receiving encouragement; (iii) there is greater intrarater reliability than inter-rater reliability; there is greater reliability in the condition WVE when compared to LVE of the examiner 1; there is greater reliability with LVE by different examiners (interrater) than by the same examiner in two different assessments (intra-rater).

\section{Method}

\section{Subjects}

Twenty healthy subjects ( 9 males; 11 females; $22 \pm 4$ years old; $170.0 \pm 9.0 \mathrm{~cm} ; 67.5 \pm 14.3 \mathrm{~kg}$; $23.3 \pm 3.6 \mathrm{~kg} / \mathrm{m}^{2}$ ) participated in the study. All subjects read and signed an informed consent form approved by the local ethics committee (no 013/16). The a priori sample size calculation was carried out using the software $G^{*}$ Power (v. 3.1.9.2) ${ }^{15}$ based on peak force mean values and standard deviation obtained by dynamometry reported by $\mathrm{MCNAIR}^{10}$. With an effect size of 0.28 , an F test, we have obtained a result of 20 subjects. We adopted a significance level of 0.05 and power of 0.80 . A posteriori, we have obtained a power of 0.83 for the tests with the sample size evaluated.

Eligibility criteria were: adult subjects not suffering from lower limbs pain for the past six months, not having passed though surgery of knees, ankles or hips in the past two years, without diagnosis of neurological or rheumatological diseases, as well as without dementia or being incapable of providing coherent information. Eligible participants should not declare any auditory deficits or language barriers, and should not be wearing lower limb prosthetics or orthotics. Participants were not allowed to perform any physical activity on the day of assessment. They were considered physically active when have been practicing more than 150 minutes of moderate or more than 60 minutes of vigorous activity per week (according to IPAQ - International Physical Activity Questionnaire) ${ }^{16}$.

In order to characterize the personality and profile of the subjects and thus investigate the influence of these aspects in task performance, we used the communication scores (from Extroversion Domain) and emotional stability scores (from Neuroticism Domain) from the Factorial Personality Battery (FPB). FPB is a psychological instrument developed from the model of the Five Great Factors: extroversion, socialization, realization, neuroticism, and openness. It has 126 questions, where the individual should point out, in a scale from 1 to 7 , how much each item describes them ${ }^{17}$. Sample subjects presented a median of 3 [IIQ 1.20] for Emotional stability domain and 4 [IIQ 1.40] for the Communication domain.

\section{Experimental protocol and types of augmented feedback}

Subjects were evaluated under five conditions in two different days one week apart. Test conditions were randomized for each subject with a pre-set sequence 
before the beginning of the experiment, for the first and second day of assessment. All subjects performed twice a maximum voluntary isometric ankle flexion sustained for 10 seconds for each condition with 1-min rest between trials, while force and EMG activity of the tibialis anterior muscle were assessed (Figure 1). We acquired two trials and adopted 1-min rest between trials to avoid fatigue during the tests.

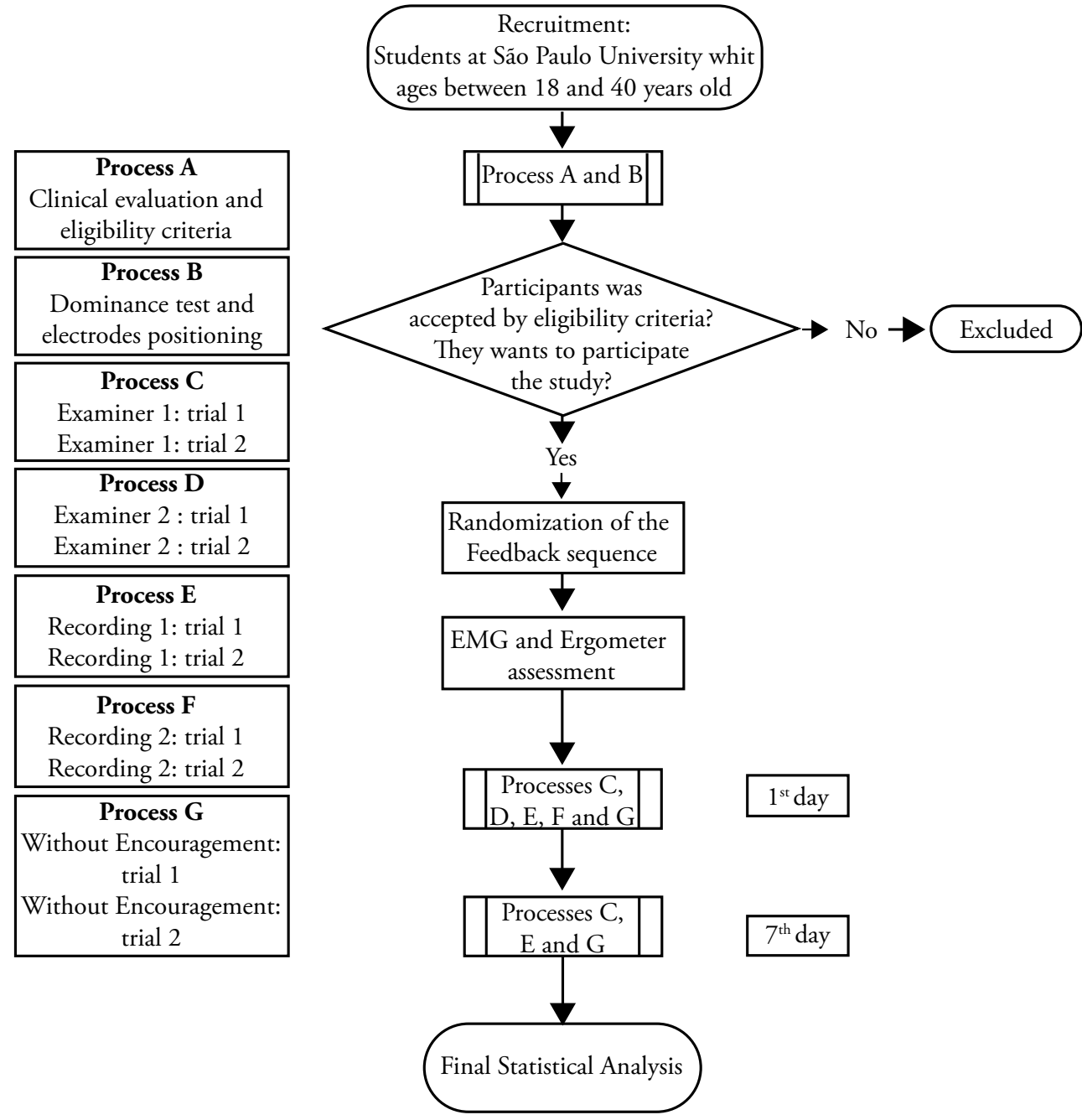

FIGURE 1 - Flow of participants throughout the study.

While performing the proposed task, participants received augmented verbal encouragement (live and recorded) delivered by two different examiners lively (Examiner 1: LVE_E1 and Examiner 2: LVE_E2) and recorded (Recorded 1: RVE_R1 and Recorded 2: RVE_R2). Examiner 1 was female and Examiner 2, male. In the live encouragement, the examiners use their voice tone, could change its intensity, but kept using the same words: "force, force, force", "go, go, go", “Stroger! You can do better!", “congratulations!”. In the recorded encouragement, the examiner recorded their standardized feedback, always in the same tone and intensity, using the words: "force, force, force" and "Stronger! You can do better!".
Participants also performed the task on both days without any encouragement (WVE). On the first day of assessment, subjects performed the ankle flexion task under all five conditions, and on the second day, they performed the conditions WVE, LVE_E1 and RVE_E1, for reliability investigation purposes.

The subjects performed the task sitting on a chair with adjustable high, lower limb properly stabilized, with the knee fully extended and the ankle positioned at $90^{\circ}$ degrees (neutral position). The ankle joint rotational axis was aligned with the dynamometer center of rotation (Figure 2). The foot was firmly strapped to the footplate connected to the strain gauge transducer using straps. The recordings 
were performed on the dominant leg, determined by asking the subject to take a step upward in a stair, kick a ball rolling toward the center of their legs ${ }^{18}$ and self-declared dominance19. If there was any discrepancy between tests, the most frequent outcome was chosen. The electromyography (EMG) signal of the tibialis anterior muscle was recorded by a wireless EMG system (EMG System do Brasil, model 800C, 8-channels, São José dos Campos, São Paulo, Brazil) with a signal amplification factor of 1000 was used. After shaving and cleaning the skin with alcohol, disposable circular adhesive electrodes of $\mathrm{Ag} / \mathrm{AgCl}$ (diameter $=10 \mathrm{~mm}$, inter-electrode distance $=20 \mathrm{~mm}$ ) were placed and attached to the skin using Transpore $3 \mathrm{M}^{\ominus}$ adhesive tape. The tibialis anterior electrode was fixed following the SENIAM recommendations ${ }^{20}$ (Figure 2). To guarantee the exact same placement of electrodes between days, a contour drawing of the electrode was made on the skin of the participants using a hypoallergenic henna tincture at the first evaluation, as a temporary tattoo. This paint remained on the skin for at least 15 days. After this period, the henna tincture gradually came out in the bath.

Ankle maximum flexion force was measured with a strain-gage load cell (traction/compression, $100 \mathrm{~kg}$ range) customized in a dynamometer (NEG1, OT Bioelettronica, Turin, Italy). Ankle flexor force were acquired amplified 100 times. EMG and force signals were sampled at $2 \mathrm{kHz}$ synchronously with a 12 bit A/D converter (OT Bioelettronica, Torino, Italy).

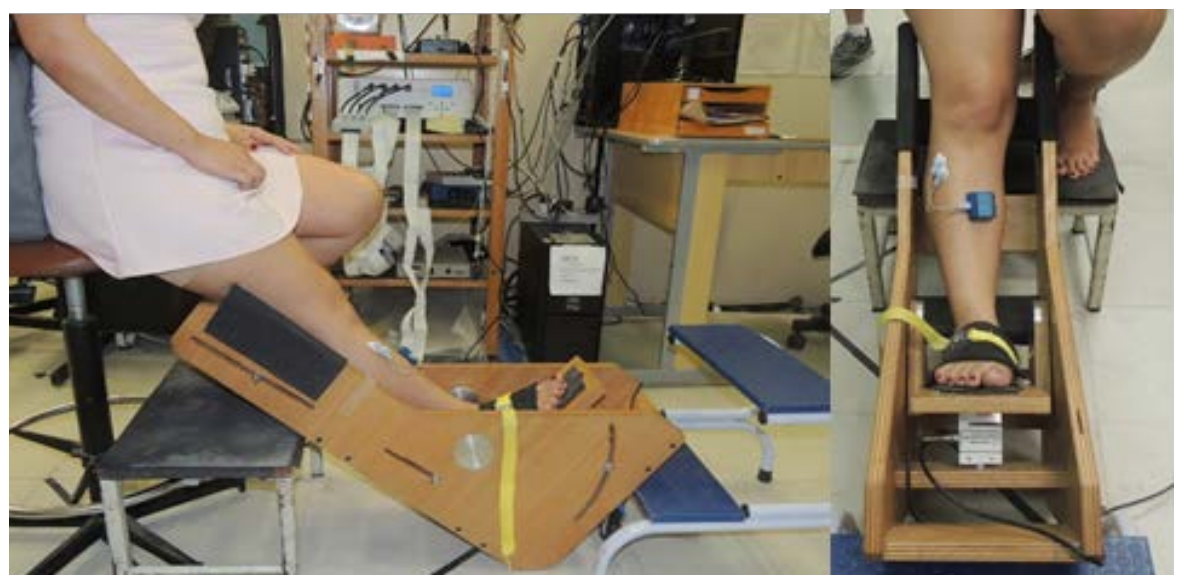

FIGURE 2 - Ankle dynamometer (OT Bioelettronica, Turin, Italy), electrode placement and position of the subject sitting on an adjustable chair.

EMG signals were filtered by a $10-500 \mathrm{~Hz}$ bandwidth 4th order Butterworth filter. The root mean square (RMS) of a centralized window of $500 \mathrm{~ms}$ of the EM signal was calculated and the means of two trials was used for statistical purposes. Force data was low-pass filtered at $10 \mathrm{~Hz}$ ( $4^{\text {th }}$ order $)$, and the mean force was computed over $500 \mathrm{~ms}$ windows with $100 \mathrm{~ms}$ overlap and the highest value was considered as the maximum force. Ankle flexor force was normalized by body mass, indirectly representing the muscle mass. The means of two trials was used for statistical purposes.

\section{Statistical analysis}

After confirmation of normality (Shapiro-Wilk test) and homoscedasticity (Levene's test), two repeated measures ANOVAs were performed for RMS and force variables for comparisons among conditions on the first day: WVE, LVE_E1, LVE_E2, RVE_E1 and RVE_E2, to verify the effect of the type of augmented feedback on the task performance. For intra and inter-examiner variability study, two-way ANOVAs $(3 \times 2)$ were conducted for each variable (RMS and force), with the feedback conditions (WVE, LVE_E1, RVE_E1) and the assessment day $\left(1^{\text {st }}\right.$ or $\left.7^{\text {th }}\right)$ considered as repeated measures.

To investigate the effects of subject's personality traits over task performance while receiving different verbal encouragements, ANCOVAs were conducted for each variable (RMS and force) comparing conditions WVE, LVE_E1, LVE_E2, RVE_E1, RVE_E2 on the first day, using as covariables Communication and Emotional stability scores from the Factorial Personality Battery. 
For intra-examiner reliability (Examiner 1), intraclass correlation coefficient $\left(\mathrm{ICC}_{2, \mathrm{k}}\right)$ was calculated, and for inter-examiners reliability (Examiner $1 \mathrm{X}$ Examiner 2), $\mathrm{ICC}_{3, \mathrm{k}}$ was calculated. To verify the measurement error, we also calculated the standard error of measurement (SEM). The ICC

\section{Results}

Comparing the values in different feedback conditions obtained by repeated measures ANOVA on the first day, no significant differences were shown between WVE, LVE_E1, LVE_E2, RVE_E1, RVE_ $\mathrm{E} 2$, for RMS ( $\mathrm{p}=0.207)$ or force $(\mathrm{p}=0.373)$.

Between days $\left(1^{\text {st }}\right.$ and $7^{\text {th }}$ day) and conditions (LVE_ E1, RVE_R1 and WVE), two-way ANOVAs (3x2) showed no significant differences for RMS (main effect "day" $\mathrm{p}=0.261$, "condition" $\mathrm{p}=0.568$, interaction $\mathrm{p}=0.936$ ) or force (main effect "day" $\mathrm{p}=0.889$, "condition" $\mathrm{p}=0.781$, interaction $\mathrm{p}=0.961$ ).

The ANCOVAs comparing the conditions WVE, LVE_E1, LVE_E2, RVE_E1 and RVE_E2 on the first day using as covariate scores of Communication and Emotional stability, evidenced no significant effect on force for Communication ( $\mathrm{p}=0.991$ ) or for Emotional stability ( $\mathrm{p}=0.991)$, and on RMS for Communication $(\mathrm{p}=0.904)$ and for Emotional stability $(\mathrm{p}=0.905)$.

Regarding WVE condition, we observed high repeatability ${ }^{22}$ for ankle force $\left(\mathrm{ICC}_{2, \mathrm{k}}=0,88\right.$, $\mathrm{SEM}=30,31 \mathrm{~N})$ and tibialis anterior RMS $\left(\mathrm{ICC}_{2, \mathrm{k}}=0.86 ; \mathrm{SEM}=10.83 \mathrm{mV}\right)$ between days of assessment. was considered a weak correlation when ICC $<0.4$, satisfactory when $0.4 \leq$ ICC $<0.75$, and excellent when ICC $\geq 0.75^{21}$.

For all analysis, an $\alpha$ of $5 \%$ was adopted and the statistical tests were conducted using SPSS v. 22 software (IBM Corp.).
Intra-examiner (repeatability) force reliability (Examiner 1) between days of assessment showed high reproducibility for condition $\mathrm{LVE} \_\mathrm{E} 1 \mathrm{ICC}_{2, \mathrm{k}}=0.87$, SEM $=32.27 \mathrm{~N}$ ) and excellent reliability for RVE_E1 $\left(\mathrm{ICC}_{2, \mathrm{k}}=0.92 ; \mathrm{SEM}=24.56 \mathrm{~N}\right)$. Intraexaminers RMS reliability was excellent for LVE_ E1 $\left(\mathrm{ICC}_{2, \mathrm{k}}=0.93 ; \mathrm{SEM}=8.46 \mathrm{mV}\right)$ and RVE_E1 $\left(\mathrm{ICC}_{2, \mathrm{k}}=0.92 ; \mathrm{SEM}=8.33 \mathrm{mV}\right)$.

Inter-examiner (reproducibility) assessment revealed excellent reliability between LVE_E1 and LVE_E2 for force variable $\left(\mathrm{ICC}_{3, \mathrm{k}}=0.98\right.$; $\mathrm{SEM}=11.80 \mathrm{~N})$ and for RMS $\left(\mathrm{ICC}_{3, \mathrm{k}}=0.92\right.$, $\mathrm{SEM}=8.88 \mathrm{mV})$. In relation to reproducibility of recorded encouragement by the both examiners, we also observed excellent reliability for force variable $\left(\mathrm{ICC}_{3, \mathrm{k}}=0.98 ; \mathrm{SEM}=12.27 \mathrm{~N}\right)$ and for RMS $\left(\mathrm{ICC}_{3, \mathrm{k}}=0.92, \mathrm{SEM}=8.16 \mathrm{mV}\right)$.

We found excellent reliability for force (LVE_E1 x RVE_R1: $\mathrm{ICC}_{3, \mathrm{k}}=0.98 ; \mathrm{SEM}=29.86 \mathrm{~N} ; \mathrm{LVE}$ E2 x RVE_R2: ICC IC, $_{1}=0.98, S E M=29.86 \mathrm{~N}$ ) and for RMS (LVE_E1 x RVE_R1: ICC $_{3, \mathrm{k}}=0.95$, $S E M=4.52 \mathrm{mV}$; LVE_E2 x RVE_R2: ICC $_{3, \mathrm{k}}=0.92$, $\mathrm{SEM}=5.72 \mathrm{mV})$.

TABLE 1 - Mean and Standard Deviation for tibialis anterior RMS and maximum ankle flexor force on different feedback conditions and assessment days

WVE: Without Verbal

Encouragement;

LVE_E1: Live Verbal

Encouragement

of Examiner 1;

LVE_E2: Live Verbal

Encouragement of

Examiner 2; RVE_E1:

Recorded Verbal

Encouragement of

Examiner 1; RVE_E2:

Recorded Verbal

Encouragement of

Examiner 2; EMG

RMS peak values:

ergometer results in

Newtons; p-values from

Repeated Measures

ANOVA and Newman-

Keuls post-hoc.

\begin{tabular}{lccc}
\multicolumn{4}{c}{ feedback conditions and assessment days } \\
\hline Condition & RMS $(\mathbf{m V} \pm \mathbf{S D})$ & Force $(\mathbf{N} \pm \mathbf{S D})$ & p (comparison with the condition WVE) \\
\hline WVE & $86.20 \pm 26.30$ & $309.34 \pm 71.29$ & - \\
LVE_E1 & $95.33 \pm 29.52$ & $315.30 \pm 74.42$ & 0.19 \\
LVE_E2 & $94.08 \pm 33.33$ & $312.86 \pm 74.57$ & 0.24 \\
RVE_E1 & $90.23 \pm 28.98$ & $300.24 \pm 70.26$ & 0.34 \\
RVE_E2 & $90.39 \pm 30.85$ & $305.86 \pm 77.96$ & 0.57 \\
\hline
\end{tabular}

\section{Discussion}

We aimed to investigate the effects of different types of verbal encouragement (live and recorded) on muscle activity of tibialis anterior and ankle flexor force and the influence exerted by communication capability and extroversion on these variables. In general, our results showed that there is no effect of any 
type of verbal encouragement on the studied variables, in addition, the personality traits of extroversion and communication did not influence the motor performance of the studied task. Furthermore, because Examiner 1 is male and Examiner 2 is female, no cross-gender effects were found from the repeated measures ANOVA performed.

We have also shown greater reliability in the presence of encouragement (live or recorded) rather than in the absence of it, even though the assessment of force and muscular activity were reproducible and repeatable.

In a different cohort from what we studied in the present work (young non-athletes), elite athletes from different sports modalities also did not changed their triceps surae muscle activation during maximal isometric contraction in the presence of verbal encouragement ${ }^{7}$. However, when the conscientiousness personality trait was taken into account as a co-variate, BıNBOĞA et al. ${ }^{7}$ observed an increase in the muscle activity in athletes with lower conscientiousness scores. CianCI et al. ${ }^{8}$ suggest that individuals who have higher levels of conscientiousness may be more predisposed to experience tension and anxiety, like any athlete. This factor may be detrimental for subsequent performance when a performance goal or high performance expectation is present. Hence, verbal encouragement, which can be perceived as "performance level is not enough and higher level of performance is required," may lead highconscientiousness athletes to experience greater anxiety, which could diminish performance.

The reason reported by BINBoĞa et al. ${ }^{7}$ to choose consciousness as a controlling variable during a strength test in the presence of feedback was because there is the predisposition to anxiety in people with high consciousness ${ }^{8}$ and this could interfere in the performance of a task due lack the attention needed in the presence of an additional external feedback $^{23}$. However, when approaching a broader population of non-athletes, Toles et al. ${ }^{24}$ found that the knee extensors strength was negatively correlated to neuroticism and positively correlated to extraversion in a longitudinal community-dwelling study with 1.220 participants. This result reported by Tolea et al. ${ }^{24}$ suggests that these personality traits (Neuroticism and Extraversion) are much more important to muscle strength evaluation than levels of consciousness, that did not show any association with muscle strength status in the performance test ${ }^{25}$. Moreover, Extraversion and Neuroticism were identified ${ }^{26,27}$ as the major components of psychological tests and intuitively connected to the idea of a motor task associated with a verbal encouragement, since the first stands for energy and enthusiasm and the second for negative affectivity. The typical extrovert person is sociable, talkative, is impatient especially in activities that persist long or that require attention to detail. In contrast, the typical introvert person is reserved, quiet and introspective, does not like agitation, and can keep attention on tasks for long periods. These characteristics imply that subjects with high scores on extraversion may be more likely to perform better on strength tasks ${ }^{24,25,28}$. Individuals with high scores in neuroticism are characterized by strong instability emotional, and therefore it is reasonable to expect better performance on motor tasks from subjects scoring low on Neuroticism as described by Tolea et al. ${ }^{24,25}$. And all these arguments were the reasons why we have chosen to use Neuroticism and Extraversion as controlling variables in our population of young non-athletes.

Concerning verbal communication, it is apparent that the amplitude and the choice of words are important factors. Therefore, as methodological care, we standardized the verbal encouragement limiting the words that were allowed to the examiners, but changing the examiner gender (male or female) and not controlling the volume he or she could speak. In the study of JoHAnsson et al. ${ }^{11}$ they observed an enhancement of $8 \%$ in strength when the sound intensity was raised in 22\%. Maybe the standardization of the verbal encouragement was the reason why participants did not change their muscle activity and force responses.

It is also possible that different results could be achieved depending on the focus of the feedback: to the task ${ }^{29}$ or only motivational, as we used. WULF and PRINZ ${ }^{30}$ have shown that an individual's focus of attention can strongly influence the motor performance. While comparing the internal (selfperception of movement) and external focus (one's body movements), the latest has shown to result in more effective performance and learning. HowEver, in physical therapy interventions or training, and in assessment contexts, the most used augmented feedback is the motivational one, and this is the reason this work was performed. Despite our study have investigated extrinsic verbal encouragement (live or recorded), the next step would be to investigate the effect of directing the focus of attention to an objective other than the task itself and evaluate this 
effect on force and muscle activity in the same simple task, as suggested by WulF and LeWTHWAIte ${ }^{29}$.

We found an excellent intra-examiner and interexaminer reliability for force and muscle activity under the influence of both verbal encouragements (recorded and live). Regardless the type of encouragement and examiner, good results can be achieved for these variables. Even though with examiners of different sexes, different voice tones and intensity, the participants perception and motor response were not influenced by these aspects and kept itself highly reliable and reproducible. It is worthy to note that the absence of augment feedback presented lower reliability when compared to the other types applied, contrary to the initial hypothesis. We hypothesized that in the absence of the examiner's influence, subjects performed the task in a uniform and constant way, with less variability. It is possible that the absence of feedback leads the subjects to perform the task differently when repeating it after a week. In the absence of feedback, the subjects only experienced their intrinsic feedback, in which they are capable of processing their own sensorial input, internalizing and understanding the need of motor adjustments in order to enhance the performance of the motor task $\mathrm{k}^{5}$ and therefore performing differently at each attempt, reducing its reliability.

Another aspect that could have influenced the results is the source of the external feedback. According to the self-determination theory ${ }^{9}$, social support is a psychological need (along with autonomy and perceived competence), which will lead to intrinsic motivation, if fulfilled. In this theory, social support produces more effect when produced by people who have high subjectivity to the individual. Therefore, if the encouragement is given by someone indifferent to the participant, it may result in a less influenced performance comparing to feedback given by their personal physiotherapist or a family member. In this context, further studies should assess the influence of different sources of external feedback to the motor performance to test this theory in simple segmental force tasks.

Given the results of the study, we can suggest that, in usual physical therapy interventions and assessments, and physical activity, it is possible interchanging the way the using of augmented feedback (live or recorded) to improve the performance of a motor task of young non-athletes. These two ways of verbal encouragement produce more reliable results than just to inform the participants about the procedure of performance of a motor task without any verbal encouragement.

Regardless the presence or type of verbal encouragement (live or recorded), the tibialis muscle activity and ankle flexor force of young non-athletes remains unaltered. The presence of augmented feedback live or recorded provided good to excellent reliability of force and muscle activity, compared to the absence of encouragement that resulted in less reliable motor responses.

Emotional aspect of the evaluators could be an intervenient variable on biomechanics variables measured, however, we have not evaluated these aspects in the present study, and we suggest a further study to investigate these influence in the feedback given and in the motor performance of subjects. It would also be interesting to further investigate the effects of verbal encouragement in individuals with depression or with discouragement conditions, which may be common in a rehabilitation scenario.

We conclude that verbal encouragement (live or recorded) does not influence ankle isometric torque or tibialis anterior muscle activity, as well as the psychological traits Communication and Emotional stability does not affect the subjects' strength performance despite of the type of verbal encouragement. We also conclude that there is a good to excellent intra and inter rater reliability for subjects' performance, regardless the verbal encouragement modality.

\section{Resumo}

\section{Efeitos de diferentes tipos de comandos verbais na força de tornozelo e na atividade muscular}

0 objetivo deste estudo é investigar (i) o efeito do comando verbal gravado ou realizado ao vivo na atividade muscular e na força isométrica de tornozelo; (ii) o efeito da comunicação/extroversão nessas variáveis; (iii) a confiabilidade intra e interavaliadores. Vinte jovens saudáveis tiveram a atividade muscular do tibial anterior avaliada por eletromiografia de superfície e a força isométrica de flexão de tornozelo avaliada por um ergômetro instrumentado em dois momentos diferentes com uma semana entre eles. Não foi encontrada nenhuma diferença significativa entre as condições avaliadas no primeiro dia tanto para RMS $(p=0.207)$ 
quanto para a força $(p=0.373)$. Não foi encontrada diferença na força do tornozelo $(p=0.961)$ e no RMS $(p=0.936)$ para nenhuma das condições envolvendo o examinador 1 . Não foi encontrada diferença entre as condições com encorajamento verbal aplicado pelo examinador 1 e pelo examinador 2, ao vivo ou gravadas, para o RMS $(p=0.207)$ ou para a força $(p=0.373)$. Entre os dias de avaliação não foi encontrada diferença significativa para nenhuma das condições avaliadas tanto para o RMS (main effect "Dia" $p=0.261$; "Condição" $p=0.568$, Interação $p=0.936$ ) quanto para a força (main effect "Dia" $p=0.889$; "Condição" $p=0.781$, Interação $p=0.961)$. A reprodutibilidade entre encorajamento verbal ao vivo do avaliador 1 e encorajamento verbal ao vivo do avaliador 2 foi alta para força de tornozelo (ICC3, $\mathrm{k}=0.98$ ) e RMS (ICC3, $k=0.92$ ). A presença de feedback aumentado não teve efeito na resposta neuromuscular ou na força isométrica de tornozelo. Concluimos que o encorajamento verbal, ao vivo ou gravado, (i) não influencia o torque isométrico de flexão do tornozelo ou a atividade do músculo tibial anterior; (ii) as características psicológicas de comunicação e estabilidade emocional não afetam o desempenho da força dos sujeitos; (iii) há de boa a excelente confiabilidade intra e inter-avaliador para o desempenho dos sujeitos, independente da modalidade de encorajamento verbal.

Palavras-chave: Comando verbal; Feedback aumentado; Eletromiografia; Força; Personalidade.

\section{Conflict of interest}

The authors affirm that this study has not received any funding/assistance from a commercial organization that could lead to a conflict of interest.

\section{References}

1. Van den Heuvel MR, Kwakkel G, Beek PJ, Berendse HW, Daffertshofer A, van Wegen EE. Effects of augmented visual feedback during balance training in Parkinson's disease: a pilot randomized clinical trial. Parkinsonism Relat Disord. 2014;20(12):1352-8.

2. Herderschee R, Hay-Smith EJ, Herbison GP, Roovers JP, Heineman MJ. Feedback or biofeedback to augment pelvic floor muscle training for urinary incontinence in women. Cochrane Database Syst Rev. 2011;(7):CD009252.

3. Onate JA, Guskiewicz KM, Sullivan RJ. Augmented feedback reduces jump landing forces. J Orthop Sports Phys Ther. 2001;31(9):511-7.

4. Schmidt RA, Lee TD. Motor control and learning: a behavioral emphasis. 5th ed. Champaign: Human Kinetics; 2011.

5. Kilduski NC, Rice MS. Qualitative and quantitative knowledge of results: effects on motor learning. Am J Occup Ther. 2003;57(3):329-36.

6. Hartveld A, Hegarty JR. Augmented feedback and physiotherapy practice. Physiother. 1996;82(8):480-90.

7. Binboğa E, Tok S, Catikkas F, Guven S, Dane S. The effects of verbal encouragement and conscientiousness on maximal voluntary contraction of the triceps surae muscle in elite athletes. J Sports Sci. 2013;31(9):982-8.

8. Cianci AM, Klein HJ, Seijts GH. The effect of negative feedback on tension and subsequent performance: the main and interactive effects of goal content and conscientiousness. J Appl Psychol. 2010;95(4):618-30.

9. Ryan RM, Deci EL. Self-determination theory and the facilitation of intrinsic motivation, social development, and well-being. Am Psychol. 2000;55(1):68-78.

10. McNair PJ. Verbal encouragement of voluntary muscle action: reply to commentary by Roger Eston. Br J Sports Med. 1996;30(4):365.

11. Johansson CA, Kent BE, Shepard KF. Relationship between verbal command volume and magnitude of muscle contraction. Phys Ther. 1983;63(8):1260-5.

12. Chitwood LF, Moffatt RJ, Burke K, Luchino P, Jordan JC. Encouragement during maximal exercise testing of type A and type B scorers. Percept Mot Skills. 1997;84(2):507-12.

13. Rube N, Secher NH. Paradoxical influence of encouragement on muscle fatigue. Eur J Appl Physiol Occup Physiol. $1981 ; 46(1): 1-7$. 
14. Campenella B, Mattacola CG, Kimura IF. Effect of visual feedback and verbal encouragement on concentric quadriceps and hamstrings peak torque of males and females. Sports Med Training Rehab. 1999;9(1):61-70.

15. Faul F, Erdfelder E, Lang AG, Buchner A. G*Power 3: a flexible statistical power analysis program for the social, behavioral, and biomedical sciences. Behav Res Methods. 2007;39(2):175-91.

16. Matsudo SM, Araújo TL, Matsudo VKR, et al. Questionário internacional de atividade física (IPAQ): estudo de validade e reprodutibilidade no Brasil. Br J Phys Act Health. 2001;10:5-18.

17. Nunes CH, Hutz CS, Nunes MFO. Bateria fatorial de personalidade. 2nd ed. São Paulo: Casa do Psicólogo; 2013.

18. Greenberger HB, Paterno MV. Relationship of knee extensor strength and hopping test performance in the assessment of lower extremity function. J Orthop Sports Phys Ther. 1995;22(5):202-6.

19. Hody S, Rogister B, Leprince P, Laglaine T, Croisier JL. The susceptibility of the knee extensors to eccentric exercise-induced muscle damage is not affected by leg dominance but by exercise order. Clin Physiol Funct Imaging. 2013;33(5):373-80.

20. SENIAM. Recommendations for sensor placement [Internet]. Enschede: The SENIAM Project; 2016 [cited 2016 Oct 2016]. Available from: http://www.seniam.org

21. Fleiss JL. Design and analysis of clinical experiments. New York: Willey-Interscience; 1986.

22. Landis JR, Koch GG. The measurement of observer agreement for categorical data. Biometrics. 1977;33(1):159-74.

23. Shahsavarani AM, Rasoolzade Tabatabaei SK, Allahyari AA, Ashayeri H, Sattari K. The effect of stress on visual selective attention regarding conscientiousness. iranian journal of psychiatry and clinical psychology. Iran J Psychiatr Clin Psychol. 2010;16(3):203-19.

24. Tolea MI, Terracciano A, Simonsick EM, Metter EJ, Costa Jr PT, Ferrucci L. Associations between personality traits, physical activity level, and muscle strength. J Res Pers. 2012;46(3):264-70.

25. Tolea MI, Terracciano A, Milaneschi Y, Metter EJ, Ferrucci L. Personality typology in relation to muscle strength. Int J Behav Med. 2012;19(3):382-90.

26. Eysenck HJ. Dimensions of personality. Oxford: Kegan Paul; 2006.

27. Eysenck HJ, Eysenck SBG. Psychoticism as a dimension of personality. New York: Crane, Russak \& Co; 1977.

28. Allen MS, Laborde S. The role of personality in sport and physical activity. Curr Dir Psychol Sci. 2014;23(6):460-5.

29. Wulf G, Lewthwaite R. Optimizing performance through intrinsic motivation and attention for learning: the OPTIMAL theory of motor learning. Psychon Bull Rev. 2016;23(5):1382-1414.

30. Wulf G, Prinz W. Directing attention to movement effects enhances learning: a review. Psychon Bull Rev. 2001;8(4):648-60.

\begin{tabular}{r|c} 
ADDRESS: & \\
Isabel C. N. Sacco & Submitted: 01/11/2016 \\
Rua Cipotânea, 51- Cidade Universitária & Revised: 03/04/2017 \\
05360-160 - São Paulo - BRAZIL & Accepted: 29/06/2017 \\
E-mail: icnsacco@usp.br &
\end{tabular}

